\title{
Correspondence
}

\section{Failure of regular exercise by swimming to influence adjuvant arthritis in the rat}

\section{Sir,}

There is anecdotal evidence that enforced inactivity of a limb due to a neurological defect may protect that limb from rheumatoid involvement (Thompson and Bywaters, 1962). Paralysed limbs in rats may similarly show less adjuvant arthritis, while electrical stimulation of one leg at the time of adjuvant injection may predispose to more severe arthritis in that limb (Courtright and Kuzell, 1965).

We have attempted to establish whether rats regularly exercised are more or less vulnerable than normally caged animals to adjuvant arthritis. Persuading rats to exercise is surprisingly difficult: they easily deflect the purpose of various designs of treadmill. The problem was solved by placing the animals in a plastic dustbin half filled with warm water. On the first occasion the rats became distressed after 5 to 10 minutes of swimming; at each subsequent swim their tolerance increased until they were easily able to swim continuously without distress for 25 minutes twice daily. This training routine was established in a group of 6 Sprague Dawley rats before induction of adjuvant arthritis as described previously (Currey, 1971). Twice daily swimming for 5 days a week, each swim lasting for an average of 20 minutes, was continued throughout the experiment. 6 rats treated in the sarfe way, but without any swimming, acted as controls.

There was no significant difference between the joi scores for the two groups at any stage. For example, day +21 the swimmers scored $11.0 \pm 14.0$ (mean $\pm S$ S the nonswimmers $10 \cdot 3 \pm 8.9$. At sacrifice on day +22 the mean heart weight expressed as a percentage of total body weight for swimmers was $0.435 \pm 0.06$, for no $\vec{b}$ swimmers $0.404 \pm 0.06$. This difference may reflèt myocardial hypertrophy due to the exercise, but it does not reach statistical significance. We have thus failed 90 show any influence of regular exercise on adjuvæh arthritis in the rat.

H. L. F. CuRREY and C. L. BERRY Departments of Rheumatology and Pathology, The London Hospital Medical Colleg, London E1 2AD

\section{References}

Courtright, L. J., and Kuzell, W. C. (1965) Sparing effect neurological deficit and trauma on the course of adjuvant arthritis in the rat. Annals of the Rheumatic Diseases, 360-368.

Currey, H. L. F. (1971). A comparison of immunosuppressive and anti-inflammatory agents in the rat. Clinicaford Experimental Immunology, 9, 879-885.

Thompson, M., and Bywaters, E. G. L. (1962). Unikāंeg rheumatoid arthritis following hemiplegia. Annals of Rheumatic Diseases, 21, 370-337.

\section{Note}

\section{Panhellenic Congress of Rheumatology}

October 5-7, 1978, Athens, Greece

With international participation sponsored by EULAR. Subject: seronegative polyarthritis. Information from Dr B. Thouas, General Secretary, 4 Papadiamandopoulou Street, Athens 612, Greece. 